\title{
Retraction Note to: Fabrication of flexible lithium-ion battery electrodes for wearable full battery with high electrochemical performance
}

\author{
Shu-Juan Gao ${ }^{1}$
}

Published online: 15 July 2020

(c) Springer Science+Business Media, LLC, part of Springer Nature 2020

\section{Retraction to: Journal of Materials Science: Materials} in Electronics (2020) 31:6716-6725 https://doi.org/10.1007/s10854-020-03228-7

The author has retracted this article [1] because it has been previously published in Chinese by another group [2].

\section{References}

1. S. Gao, Fabrication of flexible lithium-ion battery electrodes for wearable full battery with high electrochemical performance. J.
Mater. Sci.: Mater. Electron. 31, 6716-6725 (2020). https://doi. org/10.1007/s10854-020-03228-7

2. W. Yi-bo, Z. Jiu-peng, 3D printing of flexible electrodes towards wearable lithium ion battery. J. Mater. Eng. 46(3), 13-21 (2018). https://doi.org/10.11868/j.issn.1001-4381.2017.001029

Publisher's Note Springer Nature remains neutral with regard to jurisdictional claims in published maps and institutional affiliations.

The original article can be found online at https://doi.org/10.1007/ s10854-020-03228-7.

Shu-Juan Gao

2891548105@qq.com

1 Department of Chemistry and Chemical

Engineering, Lvliang University, Lvliang 033000,

People's Republic of China 